\title{
A PRÁTICA PEDAGÓGICA NO ATENDIMENTO EDUCACIONAL ESPECIALIZADO PARA O ALUNO COM DEFICIÊNCIA INTELECTUAL
}

\author{
LA PRÁCTICA PEDAGOGICA EM ATENCIÓN EDUCATIVA ESPECIALIZADA PARA \\ ESTUDIANTES COM DISCAPACIDAD INTELECTUAL
}

\section{THE PEDAGOGICAL PRACTICE IN SPECIALIZED EDUCACIONAL CARE FOR INTELECTUAL DISABLED STUDENTS}

Luci Pastor MANZOLI ${ }^{1}$

Bruna Rafaela de BATISTA ${ }^{2}$

Caio Vinicius dos SANTOS $^{3}$

RESUMO: O Atendimento Educacional Especializado - AEE está voltado para atender as necessidades dos alunos com deficiência em horários opostos aos das aulas do ensino regular. O presente estudo teve por objetivo descrever a prática pedagógica de uma professora de educação especial para desenvolver o pensamento lógico-matemático dos alunos com deficiência intelectual em uma sala de apoio especializado - AEE de uma escola estadual de uma cidade do interior paulista. Trata-se de um estudo qualitativo, de cunho descritivo e exploratório, caracterizando-se por um estudo de caso. Para coleta de dados utilizou-se os seguintes instrumentos: entrevista aberta e observação participante. Os resultados apontaram que a prática pedagógica da professora está voltada para a relação professor/aluno, na interação social e na estimulação do aprendizado, visando a construção do conhecimento para a superação das dificuldades.

PALAVRAS-CHAVE: Prática pedagógica. Deficiência intelectual. Atendimento educacional especializado.

RESUMEN: El Servicio Educativo Especializado - AEE está orientado a satisfacer las necesidades de los estudiantes con discapacidades en momentos opuestos a las clases escolares regulares. El presente estudio tuvo como objetivo describir la práctica pedagógica de un maestro de educación especial para desarrollar el pensamiento lógico-matemático de los estudiantes con discapacidad intelectual en una sala de apoyo especializada: AEE de una escuela estatal en una ciudad del interior de São Paulo. Es un estudio cualitativo, descriptivo y exploratorio, caracterizado por un estudio de caso. Para la recopilación de datos, se utilizaron los siguientes instrumentos: entrevista abierta y observación participante. Los resultados mostraron que la práctica pedagógica del profesor se centra en la relación

\footnotetext{
${ }^{1}$ Universidade Estadual Paulista (UNESP), Araraquara - SP - Brasil. Docente do programa de pós-graduação em Educação Escolar. ORCID: http://orcid.org/0000-0002-1516-0619. E-mail: luci.manzoli@unesp.br

2 Universidade Estadual Paulista (UNESP), Araraquara - SP - Brasil. Doutoranda do Programa de Pós Graduação em Educação Escolar. ORCID: https://orcid.org/0000-0002-8397-813X. E-mail: bru_tifa@yahoo.com.br

${ }^{3}$ Universidade Estadual Paulista (UNESP), Araraquara - SP - Brasil. Discente do Programa de Pós Graduação em Educação Escolar. ORCID: https://orcid.org/0000-0003-4329-4339. E-mail: casanto93@gmail.com
} 
profesor/alumno, en la interacción social y en el aprendizaje estimulante, con el objetivo de construir conocimiento para superar las dificultades.

PALABRAS CLAVE: Práctica pedagógica. Discapacidad intelectual. Servicio educativo especializado.

ABSTRACT: The Specialized Educational Service - AEE is geared towards meeting the needs of students with disabilities at times opposite to regular school classes. The present study aimed to describe the pedagogical practice of a special education teacher to develop the logical-mathematical thinking of students with intellectual disabilities in a specialized support room - AEE of a state school in a city in the interior of São Paulo. It is a qualitative, descriptive and exploratory study, characterized by a case study. For data collection, the following instruments were used: open interview and participant observation. The results showed that the teacher's pedagogical practice is focused on the teacher/student relationship, on social interaction and on stimulating learning, aiming at building knowledge to overcome difficulties.

KEYWORDS: Pedagogical practice. Inteltectual disabilitiy. Specialized educactional service.

\section{Introdução}

A educação brasileira, a partir da nova Lei de Diretrizes e Bases da Educação Nacional 9394/96, desencadeou a efetivação de um novo paradigma educacional inclusivo, garantindo princípios básicos de igualdade que beneficie a todos os cidadãos.

A partir de então, respaldados por uma série de outros documentos governamentais como decretos, leis, deliberações, dentre outros do gênero, as pessoas com deficiência tiveram assegurado o seu ingresso na escola do ensino regular e ao Atendimento Educacional Especializado - AEE, que se refere a um atendimento voltado às necessidades específicas dos alunos com deficiência. Esse ensino deve ser ofertado em horários opostos "aos das aulas das escolas comuns, com outros objetivos, metas e procedimentos educacionais" (MEC/SEESP, 2006, p. 9).

Neste sentido, "a escolarização de todos os alunos [...] realiza-se em classes comuns do Ensino Regular, [...] o Atendimento Educacional Especializado- AEE complementar ou suplementar à escolarização, pode ser desenvolvido em outro espaço escolar" (MEC/SEE, 2006, p. 7).

Esse atendimento "é um serviço da educação especial que identifica, elabora, e organiza recursos pedagógicos e de acessibilidade, que eliminem as barreiras para a plena participação dos alunos, considerando suas necessidades específicas". E a Educação Especial por sua vez, 
[...] é uma modalidade de ensino que perpassa todos os níveis, etapas e modalidades, realiza o atendimento educacional especializado, disponibiliza os serviços e recursos próprio desse atendimento e orienta os alunos e seus professores quando a sua utilização nas turmas comuns do ensino regular (SEESP/MEC, 2008).

A Resolução MEC/CNE/CEB no 4/2009 institui em seu Artigo 2º que o AEE tem como função "complementar ou suplementar a formação do aluno por meio da disponibilização de serviços, recursos de acessibilidade e estratégias que eliminem as barreiras para sua plena participação na sociedade e desenvolvimento de sua aprendizagem" (Resolução MEC/CNE/CEB no 4/2009).

De acordo com o $\S 2^{\circ}$ do Art. $2^{\circ}$ do Decreto 7.611 de 17 de novembro de 2011, esse atendimento deve "integrar a proposta pedagógica da escola, envolver a participação da família para garantir pleno acesso e participação dos estudantes, atender às necessidades específicas das pessoas público-alvo da educação especial, e ser realizado em articulação com as demais políticas públicas". No Art. $3^{\circ}$ inc. I, II, III e IV expõe:

I - prover condições de acesso, participação e aprendizagem no ensino regular e garantir serviços de apoio especializados de acordo com as necessidades individuais dos estudantes; II - garantir a transversalidade das ações da educação especial no ensino regular; III - fomentar o desenvolvimento de recursos didáticos e pedagógicos que eliminem as barreiras no processo de ensino e aprendizagem; e IV - assegurar condições para a continuidade de estudos nos demais níveis, etapas e modalidades de ensino (BRASIL, 2011).

Por meio do AAE foram implantadas salas de recursos multifuncionais como um meio específico de acesso ao currículo nas escolas do ensino regular e também em outras instituições que organizam os atendimentos educacionais especializados, oferecendo recursos e atividades complementares ao ensino comum.

No que concerne ao aluno com deficiência intelectual, o AEE visa "proporcionar condições e liberdade para que o aluno com deficiência mental possa construir a sua inteligência, dentro do quadro de recursos intelectuais que lhe é disponível, tornando-se agente capaz de produzir significado/conhecimento" (MEC SEESP/SEED/2007, p. 25).

Esclarece-se aqui que o termo "deficiência mental", por ser eivado de preconceitos, gerou discussões conduzidas pela Organização Mundial de Saúde - OMS juntamente com outros órgãos internacionais. A partir de 2007, segundo a Associação Americana de Deficiências Intelectual e de Desenvolvimento - AAIDD, foi adotada então uma nova nomenclatura, passando a ser denominada "deficiência intelectual", ao invés de mental 
(SASSAKI, 2007). Portanto, no presente trabalho aparecerão as duas nomenclaturas, respeitando-se a originalidade das citações, mas o termo utilizado pelos presentes autores é deficiência intelectual.

Segundo a Associação Americana de Deficiências Intelectual e do Desenvolvimento (AAIDD), a deficiência intelectual "é caracterizada pela limitação significativa tanto no funcionamento intelectual como no comportamento adaptativo que se expressam nas habilidades conceituais, sociais e práticas. A deficiência origina-se antes dos 18 anos de idade" (AAIDD, 2010, p. 1). Apresenta as seguintes especificações: 1) Habilidades Intelectuais; 2) Comportamento Adaptativo - Habilidades Conceituais, Sociais e Práticas; 3) Saúde; 4) Participação; e, 5) Contexto.

Para tanto, além da formação básica em Pedagogia, esses professores “devem ter uma formação específica para atuar com a deficiência a que se propõe a atender". Assim, também, "não substituem as funções do professor responsável pela sala de aula das escolas comuns que têm alunos com deficiência incluídos" (MEC/SEESP, 2006, p. 9).

Neste caso, o professor especializado precisa estar preparado para balizar suas ações, "principalmente quanto ao permitir a liberdade de tempo e de criação que o aluno com deficiência mental precisa ter para organizar-se diante do desafio do processo de construção do conhecimento" (MEC/SEESP, 2007, p. 22). Por estar envolto num sistema inclusivo, esse atendimento não segue a promoção escolar e tampouco a sequência rígida de conteúdos a serem assimilados, pois não se destina a promover alunos e, sim, possibilitar a produção do saber desassociado do dever peculiar da produção do conhecimento.

Sob essa ótica, algumas questões demandam investigação: como a professora conduz o processo ensino/aprendizagem desses alunos? Que recursos oferece para adquirirem suporte para enfrentarem o contexto das salas inclusivas? Qual a formação profissional da professora e a sua crença em relação a esses alunos?

Esclare-se aqui que a presente pesquisa é um recorte de um estudo maior que integra o Grupo de Estudos e Pesquisa na Educação Básica e Educação Especial- GEPEB/EDESP, devidamente credenciado pelo $\mathrm{CNPq}$, que congrega várias atividades acadêmico-científicas voltadas para a educação e educação especial, contexto inclusivo, práticas pedagógicas, formação do professor e suas relações políticas, epistemológicas, sociais e culturais. Portanto, as questões propostas originaram-se de um estudo que já estava sendo desenvolvido em uma escola da rede estadual, situada em uma cidade do interior do estado de São Paulo, que visava acompanhar e analisar os conhecimentos de escrita dos alunos com deficiência intelectual em salas de aula inclusivas. Considerou-se, portanto, de grande relevância analisar também a 
prática pedagógica do professor de AEE que lidava com esses alunos, resultando no presente estudo.

\section{Objetivo}

O presente estudo teve por objetivo descrever a prática pedagógica de uma professora de educação especial junto ao serviço de apoio especializado - AEE de uma escola estadual de uma cidade do interior do Estado de São Paulo, com vistas a desenvolver o pensamento lógico-matemático dos alunos com deficiência intelectual.

\section{Metodologia}

É um estudo qualitativo, de cunho descritivo e exploratório, caracterizando-se por um estudo de caso que, segundo Lüdke e André (1986, p. 17), vai estudar um único caso, [...] deve ser aplicado quando o pesquisador tiver o interesse em pesquisar uma situação singular, particular [...] e que "o caso é sempre bem delimitado, devendo ter seus contornos claramente definidos no desenvolver do estudo".

Segundo Bogdan e Biklen (1994), a pesquisa qualitativa apresenta cinco características:

1. Na investigação qualitativa a fonte direta de dados é o ambiente natural, constituindo o investigador o instrumento principal. 2. A investigação qualitativa é descritiva. 3. Os investigadores qualitativos interessam-se mais pelo processo do que simplesmente pelos resultados ou produtos. 4. Os investigadores qualitativos tendem a analisar os seus dados de forma indutiva. 5. O significado é de importância vital na abordagem qualitativa (BOGDAN; BIKLEN, 1994, p. 47).

Segundo Mattar (2001), citado por Oliveira (2011, p. 21), “os métodos utilizados pela pesquisa exploratória são amplos e versáteis [...] compreendem: levantamentos em fontes secundárias, levantamentos de experiências, estudos de casos selecionados e observação informal".

Para a coleta de dados lançamos mão da entrevista aberta e da observação participante; segundo Moreira (2002, p. 52), a observação participante é conceituada como sendo "uma estratégia de campo que combina ao mesmo tempo a participação ativa com os sujeitos, a observação intensiva em ambientes naturais, entrevistas abertas informais e análise documental". Neste sentido, os pesquisadores interagiram com a rotina da sala, visando entender o máximo possível sobre como constroem a realidade em que atuam, registrando o 
que acontece no dia a dia da vida dos alunos, implicando com isso na preparação dos observadores e de um planejamento cuidadoso.

\section{Participantes}

Participou desse estudo uma professora do AEE de uma escola estadual de periferia de uma cidade do interior paulista, diante sua atuação em uma classe composta por 5 alunos com deficiência intelectual, com idade variando de 8 a 13 anos, os quais frequentavam essa sala no contraturno do ensino fundamental I e II.

\section{Procedimentos da pesquisa}

A coleta de dados foi devidamente autorizada pela diretoria de ensino da cidade na qual o estudo foi desenvolvido, pela direção da escola e pela professora, que assinou o Termo de Consentimento Livre e Esclarecido como participante da pesquisa.

Após o aceite, devidamente autorizado, iniciou-se a coleta de dados que se deu duas vezes por semana com a duração de uma hora, sendo cada encontro num período de três meses. No decorrer dos contatos foram realizadas conversas informais com a professora sobre a sua formação, experiências e crenças a respeito do aluno com deficiência intelectual. E, para os momentos de observações, levou-se em conta a pertinência do programa estabelecido pela professora, a mediação com os alunos, os meios e materiais facilitadores do processo ensino/aprendizagem e as metas a serem alcançadas.

\section{Apresentação e discussão dos dados}

Uma breve caracterização da professora pautada nos dados da entrevista aberta nos mostra que é graduada em Pedagogia, com habilitação em Ensino Fundamental e Educação Especial. Havia realizado vários cursos de educação continuada em Educação Especial oferecidos pela Instituição em que trabalhou anteriormente, pela Oficina Pedagógica da Diretoria de Ensino de sua cidade e outros nas circunvizinhanças.

Os dados da entrevista apontaram que a professora participou de uma série de congressos na área da educação especial, cursado algumas disciplinas como aluna especial em cursos de graduação em letras e que gostava muito de ler, tanto livros literários quanto acadêmicos, e tinha proficiência na língua francesa. De acordo com a mesma, o fundamento 
de seu trabalho era voltado para a construção do conhecimento dos seus alunos, na relação professor/aluno, na interação social e estimulação do aprendizado.

Em relação à profissão, os dados da entrevista aberta evidenciam que possuía larga experiência na área da deficiência intelectual e auditiva, por ter trabalhado durante muitos anos em uma instituição não governamental para pessoas com deficiência.

Nas observações, conforme apontam nossos protocolos, em sua sala de aula as carteiras eram colocadas em forma de círculo, formando 2 grupos, sendo um com 3 alunos e outro com 2, e a cada atividade se rodiziavam, o que, segundo a professora, era para interagir uns com os outros nos seus diferentes níveis de aprendizagem e provocar uma melhor interação grupal.

Logo no início da aula um aluno já colocava uma série de livros de histórias sobre a mesa da professora e discutiam entre si para escolherem a leitura do dia e entregavam para a professora. E, em pé, na frente da sala, a professora com o livro escolhido virado para os alunos ia explicando desde o material que era feito, o número de páginas, o autor, as ilustrações, o título e depois de oferecer o panorama geral, perguntava o que a história poderia conter. Depois de especular com os alunos, lia a história e todos se mantinham com muita atenção. Após a leitura, novamente discutiam sobre o que a professora acabara de ler, e em seguida comparavam com a história que tinham hipotetizado.

Assim como nos livros de histórias, para desenvolver o pensamento lógico matemático, a professora disponibilizava para escolha uma série de jogos, sendo eles: palitos de vários tipos, cores e tamanhos; jogos de pega-varetas, fichas com número, dominó, dama, bingo, dados, jogos de encaixes de madeira dos mais variados tipos e formas geométricas; diferentes tamanhos de bolinhas de gude; jogo da velha; coleção de figurinhas (de jogadores, animais, aves); peças de encaixes (lego); grande variedade de jogos de quebra-cabeça, desde os mais simples com poucas peças, até os mais complexos de vinte a trinta peças. Também eram incentivados a trazer outros jogos que possuíam em suas casas, caso houvesse interesse em apresentar aos colegas e ensiná-los a jogar.

Os alunos, com a ajuda da professora, confeccionavam jogos de bingo e realizavam oralmente operações simples de adição e subtração e depois iam resolver na lousa, contando com a participação de todos ao fazerem a correção em voz alta com a mediação da professora.

A professora dispunha de uma grande variedade de materiais de sucata, principalmente diferentes tipos de caixas que faziam atividades destacando as formas geométricas. Utilizavam também o tangran, que são sete peças de figuras geométricas emborrachadas, sendo cinco triângulos (dois grandes, um médio e dois pequenos), um quadrado e um 
paralelogramo, ambos médios, que reunidos formavam um quadrado. Em posse desse material, os alunos conversavam entre si, cada qual com o seu, olhavam no modelo da folha de instrução entregue pela professora e montavam uma variedade de objetos e animais, e também eram incentivados a criar os próprios modelos e contar histórias sobre eles.

Outro recurso utilizado com os alunos foi a escala cuisinaire para construir conceitos básicos de matemática, para "favorecer a correspondência entre as estruturas mentais da criança e a relação que ela estabelece com as peças, através das atividades trabalhadas" (Escala Cuisinaire). É formada por 241 peças de madeira com dez cores: branca, vermelha, verde clara, rosa ou lilás, amarela, verde escura, preta, castanho marrom, azul e laranja, e tamanhos diferentes que vão de 1 a $10 \mathrm{~cm}$, onde a peça branca é padrão, de face quadrada, com medida de 1 a $2 \mathrm{~cm}$ de área, servindo de medida para todas as outras peças e equivalendo a uma unidade. (Escala Cuisinaire).

Com esse material e a mediação da professora, os alunos realizavam comparações, estabeleciam relação de grandeza, diferenciação de números, construções geométricas, números pares e ímpares; manipulação das 4 operações; resolviam problemas orais e escritos; múltiplos e divisores de um número inteiro; frações e números decimais.

A professora utilizava também os próprios alunos e os objetos existentes na sala de aula para explicar números, quantidade, cores, grandezas e medidas. Exemplificando: por meio de comparações eram levados a perceber o colega mais alto, mais baixo, mais gordo, mais magro, maior, menor, mais novo, mais velho, cor de pele e cabelos mais claros e mais escuros.

Os alunos eram levados também a perceber objetos sobre a mesa, sobre a carteira, embaixo da mesa, embaixo da carteira, sob a mesa, sob as carteiras, no alto da lousa, no baixo da lousa, a cor de suas roupas, o tamanho de seus calçados, as suas alturas, o seu pé direito, e assim por diante, estabelecendo comparações entre eles, perguntando se o braço esquerdo dos colegas era maior ou menor do que o braço direito do outro colega e indagavam o porquê, e assim procediam com as comparações.

Para ensinar categorização, distribuía caixinhas de fósforo vazias, palitos queimados de fósforo, de sorvete, pedras de diversos tamanhos, formas e cores, figurinhas e bolinhas de gude. Nessas atividades, contavam seus materiais e os dos colegas comparando-os entre si e descobrindo quem possuía mais e quem possuía menos de cada categoria desses objetos.

Trabalhava com os alunos a contagem de números de 2 em 2, 3 em 3, 4 em 4, 5 em 5 até 100 , mediante manipulação desses materiais que poderiam esparramar no chão, onde cada aluno ocupava o seu lugar nos cantos da sala para realizar a sua tarefa e depois explicava para 
o resto do grupo o que havia realizado. Eram incentivados a armar contas de adição e subtração com os materiais e depois de explicarem oralmente para a classe, ou iam resolver na lousa ou em seus cadernos, e aquele aluno que dominava mais o conteúdo poderia explicar para o colega e ajudá-lo a resolver aquela ou qualquer outra tarefa.

Para dar explicações sobre compra e venda, a professora distribuía cédulas de "dinheiro" para jogos e panfletos de preços dos supermercados e simulava a compra dos materiais discutindo os valores das mercadorias, estimulando-os a contar e pagar com o dinheiro que dispunham, perguntando se faltava ou sobrava dinheiro e como agir nesses casos. Conversavam sobre a importância de saber fazer troco, o preço dos gêneros alimentícios dos panfletos comparando os de valores iguais e diferentes, os caros e baratos, e ilustrava com probleminhas orais para apresentarem soluções.

Para trabalhar a noção de tempo, a professora distribuía vários relógios feitos de papelão, enquanto trazia em suas mãos um de tamanho maior e ia dialogando, e todos marcavam o horário de entrada em sala de aula do período anterior, a que horas saiam, o horário do recreio, o horário de entrada e saída da sala de AEE, o horário que iam dormir e o horário que acordavam. Continuava perguntando sobre o programa que mais gostavam de assistir na televisão, que horas tomavam o café da manhã, o almoço, o jantar, o tempo despendido em casa com as tarefas escolares e assim por diante. Também explorava o calendário, dialogando sobre medida do tempo, hora, dia, mês e ano, fazendo perguntas do tipo: “que dia do mês é hoje?", "Que dia da semana foi ontem? E amanhã que dia será?”, “O que fizeram na escola hoje e ontem?".

Utilizava, também, as datas de aniversários, escrevendo na lousa e incentivando os alunos a descobrirem a ordem cronológica do tempo com perguntas como: "quem nasceu primeiro? Por quê?”. Fazia comparações com outras datas, como o Natal, dia das crianças e outras comemorações importantes.

Os alunos eram levados a dialogar sobre uma variedade de assuntos como, por exemplo: cidade (praças, centros, escolas, bairros, fábricas); animais (domésticos, selvagens, aves, répteis, peixes); higiene (hábitos saudáveis de higiene corporal, alimentícia e ambiental); datas comemorativas (aniversários e datas cívicas); tempo (estações do ano, água, ar, sol) e outro de interesse da classe, bem como os fatos ocorridos na escola. A professora aproveitava a fala dos alunos e discutia a noção de distância, tomando como ponto de referência a escola.

Discutia com eles a composição familiar, número de pessoas na família, estimulandoos a falarem os nomes dos pais, dos irmãos, o sexo, as idades, o lugar que ocupavam na 
família, quem nasceu primeiro e quem nasceu por último, como eram os finais de semana em casa, com o grupo de colegas, com os parentes próximos, e por meio de desenho representar esses grupos, classificando-os por categorias.

Aproveitava ainda situações ocorridas na escola ou nessa sala e dialogava sobre a extensão de condutas sociais adequadas para um maior convívio social com a família, amigos, vizinhança, escola, dentre outros, enfatizando as expressões de cortesia: com licença, obrigado, desculpe, por favor e conscientizando-os sobre os direitos e deveres do cidadão. Neste sentido, orientava-os sobre a importância das seguintes documentações: carteira de identidade, título de eleitor, carteira de trabalho, e de como adquiri-los, ensinando os alunos a conhecer a sua impressão digital.

Segundo a professora, é de suma importância aproveitar o interesse dos alunos para vinculá-los ao programa escolar regular, sendo esse imprescindível para a inclusão social da criança. Explicitou também que o seu sistema de avaliação é o formativo ou continuado, de modo a ir além do espaço escolar, olhando-os como um ser social, capazes de aprender, e respeitando seus próprios desenvolvimentos.

Sob essa ótica, observou-se que aproveita todas as oportunidades que desperta a atenção e curiosidade dos alunos para envolvê-los numa participação mais ativa. Argumenta a professora que a aprendizagem do aluno com deficiência intelectual só se dá por meio de atividades e experiências que o leve ao contato real e consciente com o material a ser aprendido, desde que esteja adequado ao seu nível de desenvolvimento. Segundo ela, sua meta é despertar-lhes a compreensão dos fatos, melhorar suas capacidades perceptivas e de atenção, levando, assim, a maiores possibilidades de aprendizagem, integração ao meio ambiente e à uma futura profissionalização para envolverem-se no mercado de trabalho.

De acordo com Queiroga et al. (2009, s/n), a avaliação formativa "é um processo utilizado por professores e aprendizes para reconhecer e responder ao aprendizado ao longo do processo de consolidação desse aprendizado".

Neste sentido, o professor é a figura central para mediar a aprendizagem, conforme aponta Perrenoud (1999):

Pode-se ajudar um aluno a progredir de muitas maneiras: explicando mais simplesmente, mais longa ou diferentemente; engajando-o em nova tarefa, mais mobilizadora ou mais proporcional os seus recursos; aliviando sua angústia, devolvendo-lhe a confiança, propondo-lhe outras razões de agir ou de aprender; colocando-o em outro quadro social, desdramatizando a situação, redefinindo a relação ou contrato didático, modificando o ritmo de trabalho e de progressão, a natureza das sanções e das recompensas, a parcela de autonomia e representação do aluno (PERRENOUD, 1999, p. 
$105)$.

Segundo Prieto (2006), os professores:

[...] devem ser capazes de analisar os domínios de conhecimentos atuais dos alunos, as diferentes necessidades demandadas nos seus processos de aprendizagem, bem como, com base pelo menos nessas duas referências, elaborar atividades, criar ou adaptar materiais, além de prever formas de avaliar os alunos para que as informações sirvam para retroalimentar seu planejamento e aprimorar o atendimento aos alunos (PRIETO, 2006, p. 58).

Essas citações nos apontam que tanto a formação inicial do professor quanto a continuada é de crucial importância para oferecerem uma educação de qualidade a todos os alunos, principalmente no que tange à educação inclusiva para o aluno com deficiência intelectual.

Ao analisarmos a prática pedagógica dessa professora vimos aproximações à teoria Vygostiskiana, demarcados por autores contemporâneos da Psicologia Educacional, como Cavalcanti (2005), Silva et al., (2013), Nuernberg (2008), Oliveira (1997, p. 57), que nos permite refletir sobre as práticas educativas de um professor de educação especial. Segundo Vigotsky (1987), as funções mentais superiores do ser humanos se desenvolvem na relação com o seu meio social e cultural, mediadas por signos.

Pautada na teoria de Vygotsky, Cavalcanti (2005) aponta que:

[...] o pensamento, o desenvolvimento mental, a capacidade de conhecer o mundo e de nele atuar é uma construção social que depende das relações que o homem estabelece com o meio. Nessa construção, nesse processo de desenvolvimento das funções mentais superiores, tem prioridade, então, o plano interpsíquico, o interpessoal, o social (CAVALCANTI, 2005, p. 187).

Neste sentido, Silva et al., (2013) afirmam que a teoria de Vygotsky:

Coloca que o convívio da criança com o meio social vai fazer surgir uma série de dificuldades corriqueiras que vai ter que vencer. A superação das dificuldades vai empurrar o surgimento do processo compensatório. Desta forma, torna-se importante para a criança estar em interação social, principalmente, com outras da mesma faixa etária, deficientes ou não deficientes (SILVA et al., 2013, p. 20224).

Este olhar nos propõe a pensar de uma maneira dialética, que leva a comprovação de que existem problemas, mas também existem possibilidades. Nesta perspectiva, a prática pedagógica apresentada proporciona condições para que esses alunos possam superar os impedimentos a partir da interação com o ambiente, num entrelaçamento de fatores externos e internos, onde os estímulos se apresentam como suporte da superação das dificuldades. 
De acordo com Nuernberg (2008) o processo compensatório a que se refere Vygotsky:

[...] consiste, sobretudo, numa reação do sujeito diante da deficiência, no sentido de superar as limitações com base em instrumentos artificiais, como a mediação simbólica. Por isso, sua concepção instiga a educação a criar oportunidades para que a compensação social efetivamente se realize de modo planejado e objetivo, promovendo o processo de apropriação cultural por parte do educando com deficiência (NUERNBERG, 2008, p. 309).

Ressalta-se aqui que a presente professora forneceu elementos para viabilizar no ambiente de sala de aula a Zona de Desenvolvimento Proximal (ZDP) desses alunos, que de acordo com Vigotsky (1998) é:

A distância entre o nível de desenvolvimento real que costuma determinar através da solução independente de problemas, e o nível de desenvolvimento potencial, determinado através da solução de problemas sob a orientação de um adulto ou em colaboração com companheiros mais capazes (VIGOTSKY, 1998, p. 112).

Neste sentido, ficou evidente o suporte que a professora ofereceu com uma prática pedagógica que provoca a modificação das estruturas das funções psicológicas superiores, levando os alunos e a si própria a novos desafios, que exigem mais atenção, mais informação e mais conhecimentos, numa interação com o meio, contribuindo para o desenvolvimento e aprendizagem desses alunos.

De acordo com Vygotsky (1987, p. 101), “o aprendizado adequadamente organizado resulta em desenvolvimento mental e põe em movimento vários processos de desenvolvimento que, de outra forma, seriam impossíveis de acontecer”. Compreendendo o que esses alunos já conseguem realizar e o que conseguem realizar com orientação, no futuro, saberão ter autonomia para concretizar a tarefa sem a mediação da professora, consolidando, portanto, a sua aprendizagem e o seu conhecimento a respeito da tarefa em estudo.

Conforme aponta Oliveira (1997, p. 57), aprendizado é “o processo pelo qual o indivíduo adquire informações, habilidades, atitudes, valores, etc, a partir de seu contato com a realidade", significando, portanto, que o contato com o meio que o cerca é de grande importância para a concretização da aprendizagem.

Diante do exposto até então, cabe ao sistema educacional oferecer oportunidades conforme os caminhos apresentados na prática pedagógica da presente professora, com vistas a proporcionar condições para o desenvolvimento das funções psicológicas superiores, e contando com a mediação da mesma, para que, de alguma forma, as funções lesadas tenham chances de serem substituídas por formas mais superiores de organização psíquica. 


\section{Considerações finais}

Esse estudo mostrou que essa professora desempenha um papel fundamental na condução do processo ensino/aprendizagem desses alunos. O seu conhecimento é permeado de informações científicas e a sua prática pedagógica é favorável ao desenvolvimento individual e coletivo desses alunos, bem como ao estímulo do desenvolvimento da criatividade, conscientização e criticidade, com vistas a proporcionar elementos para atuarem na sociedade inclusiva.

O trabalho dessa professora nos mostrou, também, que a educação não pode olhar para o aluno com deficiência intelectual pelo aspecto da abordagem terapêutica, mas sim, considerar a pessoa e a sua interação com o meio que a cerca. Dessa forma, contribui para reduzir os déficits que podem ser mediados pelo ambiente social e cultural, o que proporciona uma absorção de conhecimentos de forma mais eficaz.

A prática pedagógica envolvida nesse trabalho fortalece a condição do aluno com deficiência intelectual no sentido de melhor lidar com o seu pensamento e raciocínio para criar e ter acesso ao conhecimento. Nesse sentido, são usadas práticas estimulantes e inovadoras com esses alunos através da dramatização, jogos, brincadeiras orais, trabalho em grupo, onde são incentivados a desenvolver a capacidade de pensar e fazer relação entre a fala e o raciocínio para a resolução dos problemas propostos. Além disso, fazem descobertas dentro de suas capacidades de aprendizagem, atingindo níveis mais complexos dentro de seu próprio ritmo de aprendizagem.

Estudos mostram que a deficiência intelectual precisa ainda de muita investigação e é objeto abrangente de pesquisa, não podendo ser definida por um único saber. Nesse sentido, a prática pedagógica do professor de educação especial necessita sempre ser reinterpretada, reestruturada e analisada para corresponder à maneira própria dos alunos com deficiência intelectual lidarem com o saber, o que, de uma maneira geral, a escola não preconiza.

Neste sentido, a aprendizagem mediada proposta por Vygosky e presente na prática pedagógica da professora em estudo revelou a sua importância para o desenvolvimento dos processos mentais superiores por meio de ações planejadas e internacionalizadas, interpostas na interação entre os alunos e o meio atuante, onde a sua prática de mediação não se delimitou apenas a trabalhos coletivos, mas também individual, oportunizando a internalização para concretizar o aprendizado. Sob essa ótica, a aprendizagem é uma atividade conjunta, mas o professor é o elemento chave de todo o processo, e os alunos, através do que foi trabalhado 
grupal e individualmente, constroem os seus conhecimentos, as suas ideias e as suas imagens a respeito do que lhes foi apresentado.

\section{REFERENCIAS}

AMERICAN ASSOCIATION ON INTELLECTUAL AND DEVELOPMENTAL DISABILITIES - AAIDD. Intellectual disability: definition, classification, and systems of supports. Washington, DC: AAIDD, 2010.

BRASIL. MEC/SEESP. Salas de recursos multifuncionais espaço para atendimento educacional especializado. Brasília, DF, 2006.

BRASIL SEEP/SEED/MEC. Atendimento educacional especializado deficiência mental. Brasília, DF, 2007.

BRASIL, Decreto 7.611 de 17 de novembro de 2011. Dispõe sobre a educação especial, o atendimento educacional especializado e dá outras providências. Diário Oficial da União, Brasília, DF, 18 nov. 2011. Disponível em: http://www.planalto.gov.br/ccivil_03/_Ato20112014/2011/Decreto/D7611.htm. Acesso em: ago. 2019.

BOGDAN, R. C.; BIKLEN, S. K. Investigação qualitativa em educação. Trad. Maria João Alvarez, Sara Bahia dos Santos e Telmo Mourinho Baptista. Porto: Porto Editora, 1994.

CAVALCANTI, L. S. Cotidiano, mediação pedagógica e formação de conceitos: uma contribuição de Vygotsky ao ensino de geografia. Cad. Cedes, Campinas, v. 25, n. 66, p. 185207, maio/ago. 2005. Disponível em: www.scielo.br/pdf/ccedes/v25n66/a04v2566.pdf. Acesso em: ago. 2019.

LÜDKE, M.; ANDRÉ, M. E. D. A. Pesquisa em Educação: abordagens qualitativas. São Paulo: EPU, 1986.

MATTAR, F. N. Pesquisa de marketing. 3.ed. São Paulo: Atlas, 2001.

MOREIRA, D. A. O método fenomenológico na pesquisa. São Paulo: Pioneira Thomson, 2002.

NUERNBERG, A. H. Contribuições de Vigotski para a educação de pessoas com deficiência visual. Psicologia em Estudo, Maringá, v. 13, n. 2, p. 307-316, abr./jun. 2008.

OLIVEIRA. M. K. de. Vygotsky: Aprendizado e Desenvolvimento, um Processo Sócio Histórico. 4. ed. São Paulo: Scipione, 1993.

OLIVEIRA, M. F. Metodologia científica: um manual para a realização de pesquisas em administração. Catalão-GO, 2011. Universidade Federal de Goiás, Campus Catalão, Curso de Administração. Disponível em:

https://adm.catalao.ufg.br/up/567/o/Manual_de_metodologia_cientifica_-_Prof_Maxwell.pdf. Acesso em: mar. 2019. 
PERRENOUD, P. Avaliação: Da excelência à regularização das aprendizagens: entre duas lógicas. Porto Alegre: Artes Médicas Sul, 1999.

PRIETO, R. G. Atendimento escolar de alunos com necessidades educacionais especiais: um olhar sobre as políticas públicas de educação no Brasil. In: ARANTES, V. A. (Org.). Inclusão Escolar. 7. ed. São Paulo: Summus, 2006. Cap. 1. p. 31-73.

QUEIROGA, F. et al. Avaliação formativa em psicologia: instrumento para análise de material instrucional. Psicologia Ciência e Profissão, v. 29, n. 4, p. 796-811, Brasília, 2009.

SASSAKI, R. K. O direito à educação inclusiva, segundo a ONU. In: A Convenção sobre os Direitos das Pessoas com Deficiência Comentada. Brasília: Corde, 2007.

SILVA, F. G. et al. Um estudo sobre a defectologia na perspectiva vigotskiana: a aprendizagem do deficiente intelectual em reflexão. In: Anais do XI Congresso Nacional de Educação - Educere. 2013. Disponível em:

https://educere.bruc.com.br/ANAIS2013/pdf/9698_6556.pdf. Acesso em: jun. 2019.

VYGOTSKY, L. S. A Formação social da mente: o desenvolvimento dos processos psicológicos superiores. São Paulo: Martins Fontes, 1987.

\section{Como referenciar este artigo}

MANZOLI, Luci Pastor; BATISTA, Bruna Rafaela de; SANTOS, Caio Vinicius dos. A prática pedagógica no atendimento educacional especializado para o aluno com deficiência intelectual. Revista Ibero-Americana de Estudos em Educação, Araraquara, v. 15, n. 3, p. 1250-1264, jul./set. $2020 . \quad$ e-ISSN: $1982-5587 . \quad$ DOI: https://doi.org/10.21723/riaee.v15i3.12965

Submetido em: 27/09/2019

Revisões requeridas em: 15/11/2019

Aprovado em: 28/12/2019

Publicado em: 20/02/2020 